Chapter 10

\title{
Bisphosphonate-Related Osteonecrosis of the Jaws - Diagnosis and Management
}

\author{
Petia F. Pechalova, Elena G. Poriazova, \\ Nikolai V. Pavlov and Angel G. Bakardjiev \\ Additional information is available at the end of the chapter \\ http://dx.doi.org/10.5772/53858
}

\section{Introduction}

The literature is replete with evidence of a new complication associated with the use of bisphosphonates defined as avascular osteonecrosis of the jaw. This chapter discusses this issue and its diagnosis and management.

\section{Background}

According to Danneman et al. [1], all cases of osteonecrosis of the jaw described until 2006 were associated with the use of the amino-group containing bisphosphonates only. Isolated reports of osteonecrosis of the jaw caused by prolonged oral administration of alendronate (Fosamax) for established osteoporosis can be found in the literature, including our previous publication. [2] Most published cases were caused by intravenous administration of a bisphosphonate. SookBin Woo et al. reported that $94 \%$ of patients were treated with intravenous pamidronate or zoledronic acid, and 6\% received oral bisphosphonates for oseoporosis or for Paget's disease. [3]

Marx in 2003 was the first to report 36 cases of "painful bone exposure of the lower and upper jaw in patients treated with bisphosphonates pamidronate and zoledronate". [4] That same year, Migliorati reported five cases [5], Carter and Gross reported four [6] and Wang reported three patients with this condition[7]. In 2004, Ruggierro et al. published 63 cases of osteonecrosis of jaw bones in patients treated with bisphosphonates. [8] In 2005, Novartis (the manufacturer of Aredia and Zometa) officially announced 475 cases of bisphosphonaterelated osteonecrosis of the jaw (BRONJ). [1] To date, numerous authors have reported cases of osteonecrosis of the jaw bones associated with the use of bisphosphonates (Table 1). [915] The global number of cases of osteonecrosis of the jaw is unknown. 


\begin{tabular}{|c|c|c|c|c|c|}
\hline Authors & $\begin{array}{l}\text { Number } \\
\text { of cases }\end{array}$ & $\begin{array}{l}\text { Disease treated with } \\
\text { bisphosphonates }\end{array}$ & Kind of bisphosphonate & $\begin{array}{l}\text { Time period from } \\
\text { start of } \\
\text { bisphosphonate } \\
\text { therapy to } \\
\text { appearance of } \\
\text { BRONJ }\end{array}$ & Site of BRONJ \\
\hline \multirow[t]{9}{*}{ Marx [16] } & 119 & Multiple myeloma - 62 & Pamidronate - 32 & 14,3 months for & - \\
\hline & & Lung cancer with bone & Zolendronate -48 & Pamidronate & \\
\hline & & metastasis - 50 & Pamidronate $\boldsymbol{n}$ Zolendronate - 36 & 9,4 months for & \\
\hline & & Prostate cancer with & Alendronate - 3 & Zolendronate & \\
\hline & & bone metastasis -4 & & 12,1 months for & \\
\hline & & Osteoporosis - 3 & & Pamidronate $\boldsymbol{n}$ & \\
\hline & & & & Zolendronate & \\
\hline & & & & 3 years for & \\
\hline & & & & Alendronate & \\
\hline \multirow[t]{10}{*}{ Ruggiero[8] } & 63 & Multiple myeloma - 29 & Pamidronate - 34 & - & Mandible-39 \\
\hline & (18 males & Lung cancer with bone & Zolendronate - 9 & & Maxilla -23 \\
\hline & and 45 & metastasis -21 & Pamidronate $\boldsymbol{n}$ Zolendronate - 13 & & Mandible plus \\
\hline & females) & Prostate cancer with & Alendronate -5 & & maxilla - 1 \\
\hline & & bone metastasis -3 & Risedronate - 1 & & \\
\hline & & Kidney cancer with & Alendronate и Zolendronate - 1 & & \\
\hline & & bone metastasis - 1 & & & \\
\hline & & Leiomyosarcoma - 1 & & & \\
\hline & & Leukemia - 1 & & & \\
\hline & & Osteoporosis - 7 & & & \\
\hline \multirow[t]{6}{*}{ Dannemann[1] } & 14 & Multiple myeloma - 7 & Zolendronate -8 & Avg. 38,7 months & Mandible-9 \\
\hline & (8 males & Lung cancer with bone & Zolendronate и Aredia - 6 & from the & Maxilla-2 \\
\hline & and 6 & metastasis - 6 & & beginning of & Mandible plus \\
\hline & females) & Prostate cancer with & & bisphosphonate & maxilla -3 \\
\hline & & bone metastasis - 1 & & medication & \\
\hline & & & & (12-71 months) & \\
\hline \multirow[t]{9}{*}{ Mavrokokki [17] } & 158 & Multiple myeloma - 31 & Pamidronate -20 & 26 doses of $62 \mathrm{mg}$ & Mandible -57 \\
\hline & & Bone metastasis - 51 & Zolendronate -43 & Zolendronate & Maxilla -24 \\
\hline & & Puget's disease -6 & Pamidronate $\boldsymbol{n}$ Zolendronate - 13 & 19 doses of 9060 & Mandible plus \\
\hline & & Osteoporosis - 26 & Alendronate - 30 & mg Alendronate & maxilla - 8 \\
\hline & & & Risedronate -2 & 14 doses of 3285 & \\
\hline & & & Clodronate -2 & mg Pamidronate & \\
\hline & & & Alendronate $и$ Risedronate - 2 & & \\
\hline & & & Alendronate $и$ Pamidronate -1 & & \\
\hline & & & Zolendronate и Ibandronate - 1 & & \\
\hline
\end{tabular}

Table 1. Several case-series of BRONJ in the literature. 


\section{Definition of BRONJ}

Bisphosphonate-related osteonecrosis of the jaw is necrosis of the jaw bone, related or unrelated to dental procedures, persisting for more than 6 to 8 weeks, refractory to conservative treatment, in patients having no history of prior radiotherapy in the affected area, treated intravenously with amino-containing bisphosphonates for at least one year, or orally for a much longer period, for a general disease causing bone resorption.

\section{Bisphosphonates}

Bisphosphonates are a class of drugs influencing bone metabolism discovered in the late 1960's. They are used to treat diseases that feature high bone resorption (multiple myeloma, osteolytic bone metastases, Paget's disease of bone [1], fibrous dysplasia [18, 19, 20], McCune-Albright syndrome [21], hypocalcaemia of malignancy) and are most commonly administered by intravenous infusion.

\subsection{Mechanism of action}

Bisphosphonates are synthetic analogues of inorganic pyrophosphates, which exert a potent inhibitory effect on osteoclast activity. They feature slow intestinal absorption; they are excreted by the kidneys without metabolic alteration and have high affinity to hydroxyapatite crystals. [22, 23] They incorporate into skeletal bones without being degraded. [24] Bisphosphonates attach to $\mathrm{Ca}^{2+}$ in areas of high bone resorption and remain integrated into the bone for more than 10 years [25] ; for example, half-life of Alendronate is 12 years [24]. They incorporate partially by pino- or phagocytosis into osteoclasts, osteoclast precursors, and also into macrophages, osteoblasts and chondroblasts. [26] Once taken, they trigger a cascade of biochemical processes leading to loss of the ability of osteoclasts to resorb bone, or even to their apoptosis. [27, 28]

\subsection{Types of bisphosphonates}

Bisphosphonates are classified based on their chemical structure (Table 2) [16, 29]

Aminobisphosphonates contain nitrogen in the side atomic chain of their molecule, with a much stronger effect. Newer aminobisphosphonates have two actions; they induce other adenosine triphosphate-analogues that cause apoptosis; and they inhibit farnesyl diphosphate synthetase, which is part of the pathological cycle of cholesterol synthesis. [30] Thus, osteoclast function is inhibited. Some authors suggest that aminobisphosphonates reduce recruitment of osteoclasts, and induce the production of osteoclast-inhibiting factors by osteoblasts. [31, 32] The chemical structure of an aminobisphosphonate is shown below [33]: 


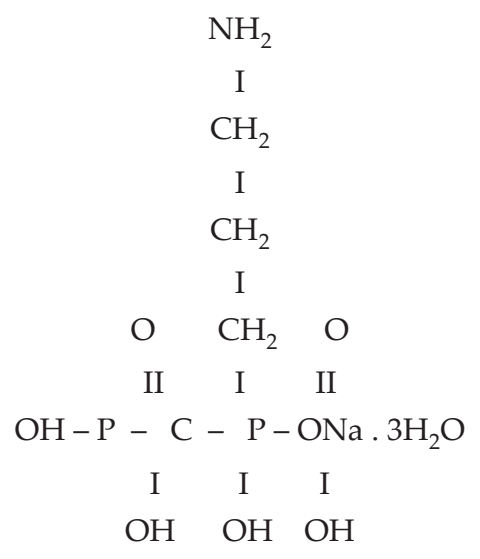

\begin{tabular}{|c|c|c|c|}
\hline Generic name & Trade name & Administration & Type \\
\hline Zoledronate & $\begin{array}{l}\text { Zometa } \\
\text { Aclasta }\end{array}$ & IV & aminobisphosphonate \\
\hline Pamidronate & $\begin{array}{c}\text { Aredia } \\
\text { Pamiton }\end{array}$ & IV/ Oral & aminobisphosphonate \\
\hline Alendronate & $\begin{array}{l}\text { Fosamax } \\
\text { Fosamax plus } D_{3} \text { Lindron }\end{array}$ & Oral & aminobisphosphonate \\
\hline Ibadronate & $\begin{array}{c}\text { Boniva } \\
\text { Bondronate }\end{array}$ & IV/ Oral & aminobisphosphonate \\
\hline Risedronate & $\begin{array}{c}\text { Actonel } \\
\text { Actonel with Calcium }\end{array}$ & Oral & aminobisphosphonate \\
\hline Tiludronate & Skelid & Oral & non-aminobisphosphonate \\
\hline Etidronate & Didronel & Oral & non-aminobisphosphonate \\
\hline Clodronate & $\begin{array}{l}\text { Bonefos } \\
\text { Ostac } \\
\text { Sindronat } \\
\text { Clodron }\end{array}$ & IV/ Oral & non-aminobisphosphonate \\
\hline
\end{tabular}

Table 2. Types of bisphosphonates.

Non-aminobisphosphonates - metabolized by osteoclasts to inactivate non-hydroxylysine adenosine triphosphate-analogues that have a direct cytotoxic effect and lead to apoptosis. [3] The chemical structure is shown below [33]: 


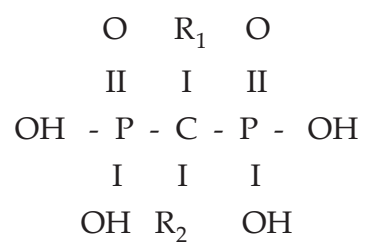

Until recently, bisphosphonates were administered predominantly as an intravenous infusion. Now, bisphosphonates in the form of tablets for oral administration are recommended for patients with osteoporosis. The management strategy for osteoporosis is to prevent osteoclast-mediated resorption of trabecular bone, and thus, maintain its density.

\subsection{Bisphosphonate use}

More than 2.5 million patients worldwide have been treated with bisphosphonates. [34] Almost 2 million people receive treatment with bisphosphonates as part of their anticancer therapy. [1] The number of patients treated with oral bisphosphonates for osteoporosis has also been growing. In 2003 Alendronate was the $19^{\text {th }}$ most commonly prescribed drug in the world (17 million prescriptions), Risedronate was the $72^{\text {nd }}$ with 6 million prescriptions, and Zolendronate was taken by over 300,000 patients. [35, 36]

\subsection{Adverse effects}

Bisphosphonate therapy can lead to some adverse effects i.e. kidney failure [37], arthralgia, fever, muscle pain and [38] hypocalcaemia [39]. In vitro and in vivo tests reported antiangiogenic (hence antitumour) effect of Zoledronic acid by inhibiting endothelial cell proliferation and induction of apoptosis. [23, 40]

\subsection{Possible mechanism leading to BRONJ}

BRONJ probably results from suppression of bone metabolism established after bisphosphonate treatment and from accumulation of physiologic microtraumas to the jaw bones, compromising biomechanical properties. Trauma and infection increase the need for bone recovery, which exceeds the capacity of hypodynamic bone, thus resulting in localized bone necrosis. Antiangiogenic properties of bisphosphonates and other medications taken by patients, and the presence of other comorbid factors may promote the risk of development, persistence or progression of this condition. [3]

\section{BRONJ}

Sook-Bin Woo et al. assume that bisphosphonate-associated osteonecrosis develops only in the jaw bones because they, unlike other bones in the body, are not sufficiently protected. On one hand, an important fact is that they are protected from possible intraoral trauma only by thin mucosa and periosteum. On the other hand, the presence of teeth in the jaw bone 
is a prerequisite which facilitates penetration of microorganisms and development of intraosseous infections via deep caries complications and the periodontium. [3] In fact, one case of bisphosphonate-associated osteonecrosis of the auditory canal in a patient treated with Zoledronic acid in relation to multiple myeloma, published by Polizzotto et al. can be found in literature; the lesion appeared after removal of exostoses in the external auditory canal, but even in this case the patient had a concurrent osteonecrosis of the maxilla. [41]

\subsection{Incidence of BRONJ}

Reports on the incidence of the disease are variable. Most authors present statistical studies of patients with multiple myeloma and lung cancer; the largest groups treated with bisphosphonates was a study of 1203 cases, of which 904 patients with multiple myeloma and 299 with lung cancer. Development of osteonecrosis of the jaw bones was found in $7 \%$ and $4 \%$, respectively. [3] Bamias et al. studied 252 patients receiving intravenous bisphosphonate therapy; $10 \%$ of patients with multiple myeloma and $3 \%$ of patients with lung cancer developed osteonecrosis of the jaw bones. [39] Estilo et al. studied 124 patients with multiple myeloma and lung cancer treated with intravenous bisphosphonates and found that osteonecrosis of the jaw bones developed in 4 patients with myeloma and in 9 patients with lung cancer. [42] Bilezian stated that the incidence of BRONJ is 1.3\%. [33]

\subsection{Clinical presentation}

Clinically intraoral lesions in BRONJ look like zones of yellow-white hard bone, with soft or indurated borders (Figs. 1-3).

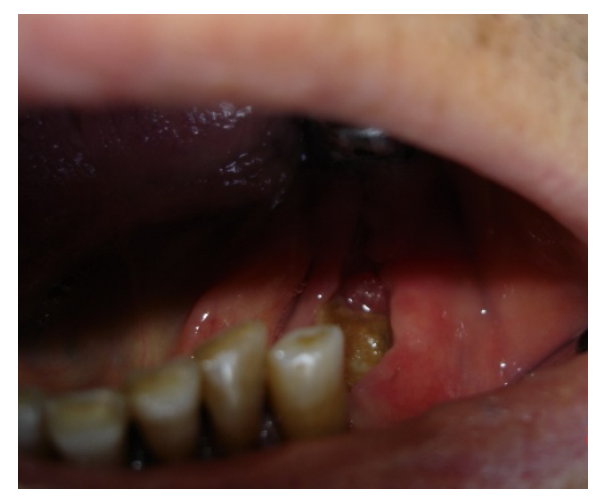

Figure 1. BRONJ of the mandible. 


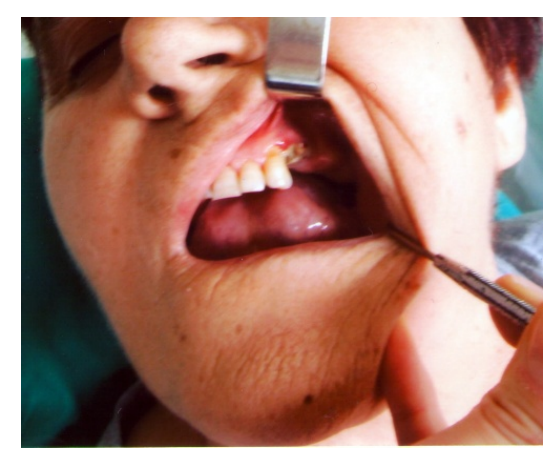

Figure 2. BRONJ of the maxilla.

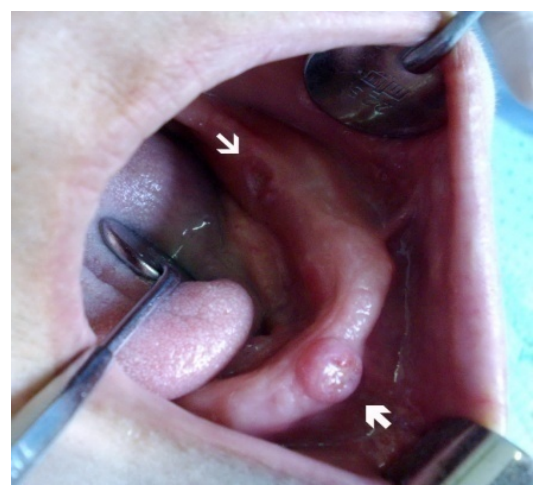

Figure 3. Multiple lesions of the mandible

Extra-or intraoral fistulas may be found. Painful lesions may develop in the soft tissues; they may conflux with the exposed bone and may involve large regions of the mouth. Some cases of pathological fracture of the mandible as the first manifestation of the disease have been described. [40] Danneman et al. suggest that unlike osteoradionecrosis, osteonecrosis of the jaw has no preference for the mandible and it affects both mandible and maxilla. [1] SookBin Woo et al. in an overview of 368 cases, reported involvement of the mandible in $65 \%$ of the cases, the maxilla in $26 \%$ and in both jaws in $9 \%$. The ratio of women to men was 3:2. The same author reported that most of the lesions were in the posterior regions of the mandible, near the mylohyoid ridge. According to him, multifocal/ bilateral lesions were slightly more frequent in the maxilla (31\% compared to the mandible which was $23 \%$ ). [3]

\subsection{Paraclinical tests}

In the early stages of the disease there may be no radiological changes. [3] Some authors recommend performing computed tomography. [33] Chiandussi et al. suggest that later 
changes in jaw bones in bisphosphonate-associated osteonecrosis can be visualized by radiography, and for early detection of lesions it is necessary to perform computed tomography examination or MRI. [43] Dunstan et al. recommend jaw bone scintigraphy with Tc-99m methylene diphosphonate. [44] In advanced cases, the bone shows a moth-eaten appearance [41] clearly identifiable radiologically with or without X-ray positive sequestra. Danneman et al. argue that the sequestra typical of chronic osteomyelitis are not found in BRONJ. [45]

Microbiological testing most commonly finds actinomycete druses. [1, 46]

Histopathological analysis shows presence of necrotic bone surrounded by bacteria that do not enter into it. [40] Three main histological patterns have been identified in BRONJ patients [47] (Fig. 4):

1. Areas with active acute inflammation, characterized by predominance of soft tissues, inflammatory infiltrate, acellular necrotic debris, thin-walled and dilated blood vessels, and intensely basophilic bone spiculae with scalloped borders showing prominent bone resorption.

2. Areas characterized by predominance of bony structures showing wide acellular necrotic sequestra and large, scalloped Haversian canals containing inflammatory cells.

3. Non-necrotic areas containing larger amounts of bone, showing increased trabecular thickness, inter-osteonic bone deposition and smaller and fewer Haversian canals. Also, lamellar bone from treated patients was composed of bigger osteones containing larger osteocytes. Two different types of newly-formed woven bone, mainly showing centrifugal spatial orientation, were easily detectable in these areas. Osteoclast-like cells detected in inflammatory areas from treated patients were small and contained few nuclei, but they were rare to absent in non-necrotic bone from the same patients.

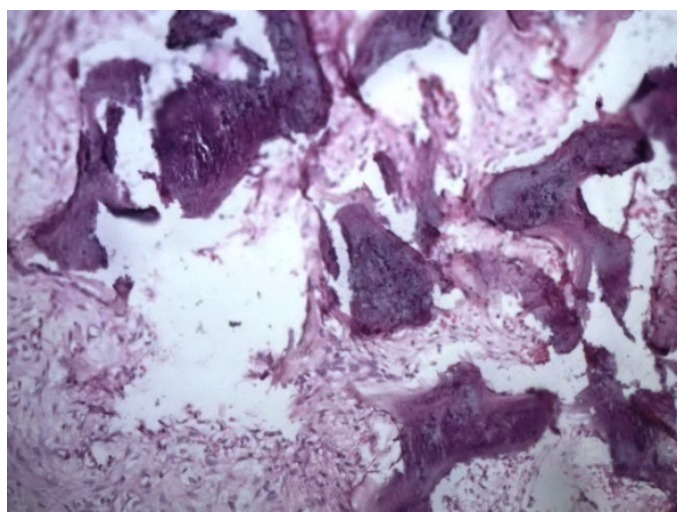

Figure 4. Microscopic view of necrotic bone in BRONJ. 


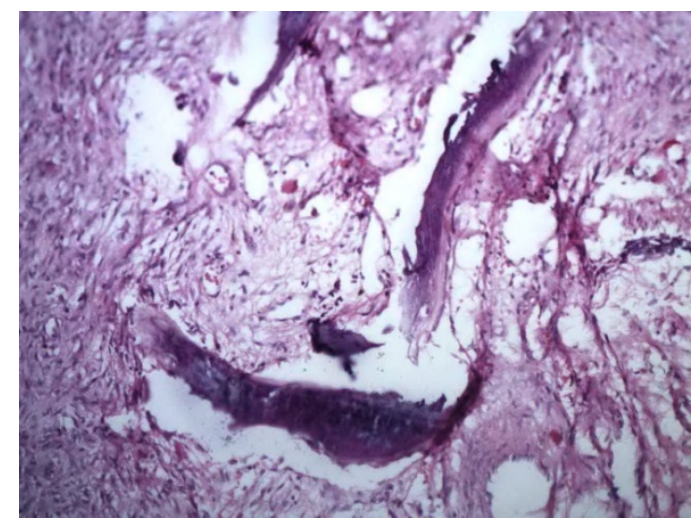

Figure 5. Another microscopic view of necrotic bone in BRONJ

\section{Differential diagnosis}

Differential diagnosis of ONJ includes [48]:

- Malignancies - differentiation is through histopathological analysis;

- Osteoradionecrosis if jaws were exposed to prior radiation;

- Osteomyelitis in which, unlike bisphosphonate-associated osteonecrosis, necrotic bone is surrounded by vital bone, which reacts with a violent inflammatory reaction, thus limiting necrosis;

- Osteopetrosis - an extremely rare congenital condition;

- Bone necrosis in HIV-positive patients.

\section{Risk factors for development of BRONJ}

Mainly two groups of factors responsible for the development of jaw necrosis may be found in literature - the first one investigates the bisphosphonate administered (type, regimen and period of treatment), and the other one investigates the dental diseases and procedures that are likely to mediate the onset of the condition.

\subsection{Risk factors associated with bisphosphonates}

- Kind of bisphosphonate that induces BRONJ more often

According Danneman et al., all cases of osteonecrosis of the jaw described until 2006 were associated with the use of the amino-group containing bisphosphonates only. In literature 
there is no consensus on the question which amino-bisphosphonates cause more frequent development of BRONJ (Table 3), but scientific evidence supports the predominant view that the use of Zoledronic acid is the most risky. [39, 45, 49, 50]

\begin{tabular}{lcccc}
\hline & $\begin{array}{c}\text { Dannemann et al. } \\
\text { [45] }\end{array}$ & Badros et al. [51] & Clarke et al. [52] & Durie et al. [50] \\
\hline $\begin{array}{l}\text { Total number of patients undergoing } \\
\text { bisphosphonate treatment }\end{array}$ & 23 & 22 & 497 & 1203 \\
\hline Number of cases with BRONJ & 14 & 2 & 5 & 21 \\
\hline $\begin{array}{l}\text { Number of patients that received } \\
\text { Zolendronate }\end{array}$ & 5 & 17 & 8 & - \\
\hline $\begin{array}{l}\text { Number of patients that received } \\
\text { Pamidronate and Zolendronate }\end{array}$ & 1 & 3 & 10 & 17 \\
\hline $\begin{array}{l}\text { Number of patients that received } \\
\text { Pamidronate }\end{array}$ & 3 & - & 2 \\
\hline $\begin{array}{l}\text { Number of patients that received } \\
\text { Alendronate }\end{array}$ & & & 25 \\
\hline
\end{tabular}

Table 3. Development of BRONJ in patients receiving different types of bisphosphonates.

\section{- Regimen}

A safer regimen for bisphosphonate treatment in terms of developing BRONJ

Corso et al. published a study of multiple myeloma patients, divided into two groups; the first group received bisphosphonate treatment under the standard regimen, i.e. monthly; while the patients in the second group received bisphosphonates monthly in the first year, and then at every third month. They found, with statistical reliability, fewer cases of BRONJ in patients from the second group, while in the first group they found cases of jaw necrosis after the first year of the initiation of treatment. The authors reported that the Skeletal-Related Events (SRE) index, which takes into account the condition of the bone system as a whole, was comparable in both groups. [49]

\section{- Duration of treatment}

Relationship between the period of use of bisphosphonates and the risk of developing bronj

Bamias A et al. suggest there is a strong correlation between the duration of treatment with bisphosphonates and manifestation of jaw necrosis; they found that the average period of exposure to drugs in patients with BRONJ was 39.3 months (from 11 to 86 months) and in patients without BRONJ was 19 months (from 4 to 84.7 months); and they defined the risk of developing the condition to be from $1 \%$ at 12 months after the start of treatment to $11 \%$ in the fourth year. The authors reported that these figures vary depending on the type of bisphosphonate administered ( in patients treated with Zoledronic acid only it was from 1\% in 
the first year to $21 \%$ in the third year since initiating the treatment, while in patients treated with Pamidronate with or without Zoledronic acid it was $0 \%$ in the first two years of treatment and up to only 7\% after four years of treatment). [39] Corso A. et al. determined the following periods for the development of BRONJ depending on the bisphosphonate administered; in case of treatment with Pamidronate, necrosis was observed no earlier than 23 months after initiation of therapy; in case of administration of Zoledronic acid this period is no shorter than 28 months; in concomitant use of Pamidronate and Zoledronic acid necrosis can be observed no sooner than 43 months. [49] Badros et al. suggest that with each year after diagnosing multiple myeloma and its treatment, the risk of developing BRONJ is increases by $57 \%$. [4]

\subsection{Risk factors related to the dento-alveolar system}

- Anatomical comorbidity

This group of predisposing factors considers the presence of mandibular tori, palatal tori, and bone exostoses as sites more easily subject to local traumatization during daily activities. Marx et al. reported BRONJ in $9.2 \%$ on mandibular tori. [16]

- Diseases of dental hard tissues and supporting apparatus

Marx et al. found that the most frequent dental disorder concomitant with BRONJ is symptomatic or radiologically diagnosed periodontitis in $84 \%$ of patients. Caries in necrotic areas was registered in $28.6 \%$. [16]

- Dental procedures:

Literature is replete with the incidence of bisphosphonate-associated osteonecrosis of the jaw associated with previous dental procedures compared to cases of the so-called spontaneous BRONJ. [4, 18, 27, 28, 35, 39, 53] Woo Sook-Bin et al. [3] found that 33\% - 86\% of cases of BRONJ reported in the literature occurred after different dental procedures (Table 4 ).

\begin{tabular}{lccc}
\hline & Marx [16] & Dannemann [1] & Bamias [39] \\
\hline Total number of cases with BRONJ & 119 & 23 & 17 \\
\hline Number of cases with BRONJ after tooth extraction & 45 & 34 & 2 \\
\hline Number of cases with BRONJ after endodontic treatment & 34 & 2 \\
\hline Number of cases with BRONJ after new or uncomfortable & & 1 \\
denture & 5 & 1 & \\
\hline Number of cases with BRONJ after periodontal surgery & 4 & \\
\hline Number of cases with BRONJ after apecoectomia & 4 & \\
\hline Number of cases with BRONJ after dental implants & & \\
\hline
\end{tabular}

Table 4. Dental procedures as a risk factor to development of BRONJ 


\subsection{Other risk factors}

The literature discusses the role of therapy concomitant with bisphosphonate treatment. Immunosuppressive effects of chemotherapy, impaired bone remodelling during treatment with glucocorticoids, antiangiogenesis properties of Thalidomide slow down the reparative processes in the oral cavity, and are a predisposing factors for the manifestation of BRONJ. [54]

Each decade of age passed increase the risk of developing BRONJ by $9 \%$. [4]

\section{Where to refer the patient if BRONJ is suspected}

If development of BRONJ is suspected, the patient should be referred to an oral or a maxillofacial surgeon. Nastro et al. [55] emphasize the important role of these specialists and emphasize that their intervention should not be underestimated. However, in all cases, treatment should be conducted jointly with the specialist who prescribed the bisphosphonates (the oncologist, haematologist, endocrinologist, etc.).

\section{Termination of bisphosphonate therapy after diagnosis of BRONJ}

There is no consensus on the need for discontinuation of bisphosphonate treatment after diagnosing osteonecrosis of the jaw. Marx suggests that behaviour in terms of bisphosphonate therapy in cancer patients shall be discussed with the oncologist on the purpose of determining the benefit to risk ratio, in view of the long half-life (10 years) of bisphosphonates. [16] Other authors share the same opinion. [48, 55] Dunstan et al. suggest that bisphosphonate therapy be discontinued. [44]

\section{Algorithm of actions following development of BRONJ}

By summarizing the evidence found in literature, the following algorithm for treatment of patients suspected to have BRONJ can be derived:

1. A careful clinical examination to find the location and volume of exposed necrotic bone

2. Imaging diagnostics of the affected jaw - X-rays, CT scans, MRI, bone scintigraphy

3. Providing material for histopathological analysis to exclude the presence of a systematic process in the jaw (in case of multiple myeloma, a metastasis in case of oncological diseases or a primary neoplasm)

4. Providing material for microbiological examination with emphasis on fungal or other pathological bacterial infections 
5. Treatment - It is assumed that BRONJ is an irreversible condition. [55, 56] Medical treatments are aimed at elimination or control of pain and at prevention of progression of jawbone exposure. Necrotic bone itself is not painful - pain, cellulitis and cutaneous fistulas occur in case of secondary infection. Thus, a long-term and sometimes permanent antibiotic treatment is recommended.

- Drug therapy - systematic medication treatment includes the triad:

- antibiotic

- antifungal agent

- antiviral agent

The first choice antibiotic is oral penicillin (Table 5).

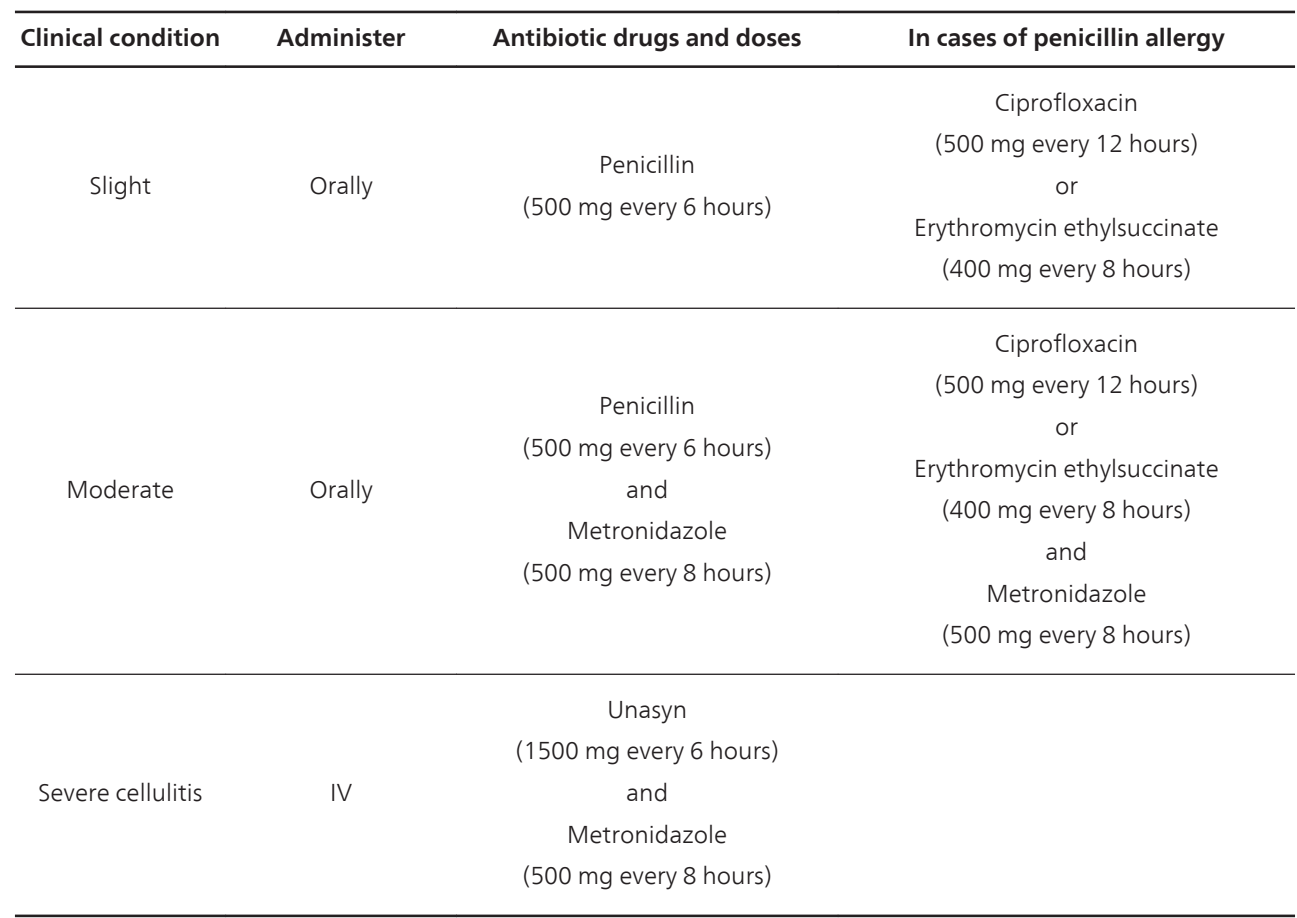

Table 5. Antibiotic treatment for control of diagnostic BRONJ by Marx et al. [16]

It is advisable that the therapy also include $0.12 \%$ chlorhexidine mouth rinse solution. [16] Penicillin may be replaced with Dalacin C (600 mg at every 8 hours) or Doxycyclin (100 mg every 12 hours for the first 24 hours, and $100 \mathrm{mg}$ for every 24 hours after that). The American Dental Association recommends the following oral antibiotics: Amoxicillin with or without Metronidazole, and in case of penicillin allergy Clindamycin or Azithromycin (Table 6). 


\begin{tabular}{ccc}
\hline Drugs & Doses & Duration of treatment \\
\hline AMOXICILLIN & 500 mg every 8 hours & 14 days \\
\hline METRONIDAZOLE & 250 mg every 8 hours & 14 days \\
\hline CLINDAMYCIN & 300 mg every 8 hours & 14 days \\
\hline AZITROMYCIN & 250 mg daily & 10 days \\
\hline
\end{tabular}

Table 6. Antibiotics for oral use in BRONJ recommended by the American Dental Association [53]

Dunstan et al. [44] identified Penicillin, Clindamycin, Erythromycin, Nystatin, Fluconazole, Acyclovir, Valocyclovir (for systemic use) and $0.12 \%$ chlorhexidine gluconate, minocycline hydrochloride (mouth rinse) as typical drugs for treatment of osteonecrosis of the jaw. Marx et al. suggest that the administration of Clindamycin only is not recommended because of its ineffectiveness in terms of most frequently detected microorganisms in the exposed bones, namely actinomycetes, Eikenella corrodens and other similar types. [16] Nastro et al. emphasize that antibiotics cannot penetrate into necrotic tissue, so they are used only for treatment of cellulitis of the tissue adjacent to bone necrosis. [55]

- Surgery (debridement of the wound and covering it with an adjacent flap) - a method of choice which most authors do not recommend [5, 8], because of the danger of involving new bone sections in the process. Marx et al. [16] reports that pathological fractures in bisphosphonate-associated osteonecrosis of the jaw are extremely rare, except in cases where debridement had been performed, thus weakening the bone. That is why he recommends only smoothening of sharp bone edges that contribute to inflammation and pain in the affected area. Dunstan et al. [44] recommends avoiding surgery when the process starts, but argues that in some cases partial mandibulectomy or maxillectomy is required, emphasizing the idea of sparing debridement. Nastro et al. [55] also are not supporters of surgery - they published a series of 12 cases, only one of which was treated surgically, and subsequently a recurrence developed in the same location of the jaw. Graziani et al. recommended performing sequestrectomy and resection in certain cases but the treatment protocol to which they adhered to included primarily antibiotic treatment, combined with periodic debridement to remove necrotic areas aimed at reduction of symptoms. [57] In the literature, there is an underlying view that aggressive surgical treatment is counterproductive and leads to deterioration and therefore should be avoided. $[5,8,16,44]$

- Hyperbaric oxygenation ( the evidence for its efficacy is controversial) application result rather from the analogy with the treatment of osteoradionecrosis, in which stabilization of the oxygen gradient is used. The mechanism of development of osteoradionecrosis and BRONJ, however, is fundamentally different. [16] The prevailing opinion in the literature is that hyperbaric oxygenation has no definite effect on the response of osteonecrosis of the jaw, and its use is not recommended. $[8,44,55,56]$ 
- Ozone therapy, an experimental method of treatment, studied by Agrillo et al. [38], published a series of cases treated by the following regimen:

- Minimally invasive surgical curettage under local anaesthesia - the authors reported the removal of necrotic bone in search of vascularized tissue, and limited deperiostealization to mobilize the mucosal flap covering the bone wound;

- Medical treatment, including the antibiotic triad (amoxicillin with clavulanic acid, 1000 $\mathrm{mg}$ at every 12 hours) antifungal agents ( $250 \mathrm{mg}$ at every 8 hours) and antiviral agents (800 mg daily) for 20 days, and also vitamin C (3000 mg per day) for 20 to 30 days, local antiphlogistic agents and $0.2 \%$ chlorhexidine mouth rinse.

- Ozone therapy with Ozonytron - pre-, intra-and postoperatively (2 applications, each lasting for 5 minutes, per week, for 20 days) and repeating the course at the onset of pain or a diagnosed infection.

Ozone has a positive effect on the bone defect by oxidation and stimulation and/or preservation of endogenous antioxidant systems, and by blocking the xanthine/xanthine oxidase pathological cycle. Ozone has a beneficial effect on blood circulation, it increases the number of red blood cells and hemoglobin levels, accelerates diapedesis and phagocytosis and stimulates the reticulohistiocytic system. The described effects are most pronounced in small diameter vessels, such as the jaw vessels and capillaries. [9] Clavo et al. reported that ozone is harmless to living tissue, and at certain concentrations it has analgesic effects. [58] Agrillo et al. made the conclusion that ozone can be used in the treatment of patients with avascular necrosis of the jaw due to its stimulating effects on the metabolism of oxygen, calcium, phosphorus and iron. [38]

\section{Prevention of BRONJ}

At this stage there is no evidence-based therapeutic strategy for BRONJ and the condition is considered to be irreversible, and therefore the attention of medical community focuses on the possibilities of its prevention. [3, 53, 59, 60, 61, 62]

\subsection{Before the start of bisphosphonate therapy}

After establishing diagnosis requiring treatment with bisphosphonates, but before initiating the therapy, the patient should be referred to a dentist and an oral or a maxillofacial surgeon. The following plan for behaviour is recommended:

1. A thorough clinical examination of the dentition and oral cavity, panoramic radiograph and, by the discretion of the doctor, targeted periapical radiographs as a mandatory required minimum.

2. Conducting dental treatment aimed at elimination of infection and the need for invasive procedures in the short- and mid-term future (Table 7). 


\begin{tabular}{|c|c|c|c|c|}
\hline Procedure & Interventions & $\begin{array}{l}\text { Antibiotic } \\
\text { prophylaxis }\end{array}$ & Standard drugs & $\begin{array}{l}\text { Drugs in cases of } \\
\text { penicillin allergy }\end{array}$ \\
\hline $\begin{array}{l}\text { Invasive dental } \\
\text { procedures }\end{array}$ & $\begin{array}{l}\text { - Tooth extractions } \\
\text { - Periodontal surgery } \\
\text { - Endodontic treatment } \\
\text { - Excision of tori and } \\
\text { exostosis } \\
\text { - Extraction of impacted } \\
\text { teeth }\end{array}$ & Recommended & Penicillin & $\begin{array}{l}\text { Ciprofloxacin } \\
\text { and } \\
\text { Metronidazole } \\
\text { or } \\
\text { Erythromycin } \\
\text { and } \\
\text { Metronidazole }\end{array}$ \\
\hline $\begin{array}{l}\text { Non-invasive } \\
\text { dental } \\
\text { procedures }\end{array}$ & $\begin{array}{l}\text { - Prophylaxis } \\
\text { - Flouridization } \\
\text { - Filling caries }\end{array}$ & Not recommended & & \\
\hline
\end{tabular}

Table 7. Antibiotic prophylactic in cases of dental procedures preceding bisphosphonate treatment

It is appropriate that the specialized surgery in the oral cavity be in compliance with the following recommendations:

- In terms of mandibular and palatal tori and exostoses, their removal is recommended only in case of large and lobed structures covered with thin overlying mucosa.

- In terms of impacted teeth, surgical removal is recommended only for those which are not fully covered by bone, communicating with the oral cavity, because of the danger of onset of an inflammatory process in the future.

- Patients subject to bisphosphonate treatment are not eligible for restoration with dental implants.

All invasive dental procedures should be performed at least one month before initiating bisphosphonate therapy in order to allow sufficient time for recovery of the jawbone.

\subsection{After the start of bisphosphonate therapy}

After the start of bisphosphonate therapy patients are subject to preventive check-ups at every four months, with radiographic examination, which should seek vigilantly for the presence of osteolysis, osteosclerosis, and expansion of periodontium and involvement of furcations. If additional treatment is required, non-invasive dental procedures are preferred. Elective surgery does not lead to encouraging results. Placing dental crowns is permissible. Removable dentures should be carefully planned in areas of expected excessive pressure, giving preference to soft plastic structures. [16]

\section{Conclusion}

Bisphosphonate-associated osteonecrosis of the jaw bones is a newly discovered entity that should be taken into account by dentists, hematologists, oncologists, endocrinologists and 
other medical professionals in their daily practice. At this stage, it is assumed that the condition is irreversible. Therefore, efforts are focused on prevention and early diagnosis through various paraclinical methods, if possible before clinical manifestation.This condition is subject to further study. [63]

\section{Author details}

Petia F. Pechalova ${ }^{1 *}$, Elena G. Poriazova ${ }^{2}$, Nikolai V. Pavlov ${ }^{3}$ and Angel G. Bakardjiev ${ }^{4}$

*Address all correspondence to: pechalova@yahoo.com

1 Department of Maxillo-Facial Surgery, Faculty of Dental Medicine, Medical University, Plovdiv, Bulgaria

2 Department of Pathology, Medical University, Plovdiv, Bulgaria

3 Private Practice of Oral Surgery, Plovdiv, Bulgaria

4 Department of Oral Surgery, Faculty of Dental Medicine, Medical University, Plovdiv, Bulgaria

\section{References}

[1] Dannemann C. Gratz KW, Zwablen R. Clinical experiences with bisphosphonates induced osteochemonecrosis of the jaws. Swiss Medical Weekly 2006; 136: $504-509$.

[2] Pechalova P, Bakardjiev A, Vladimirov B, Poriazova E, Zaprianov Z, Angelova I, Zheleva A. Osteonecrosis of lower jaw, associated with the application of oral bisphosphonates - case report. Journal of Clinical Medicine 2009; 2(2): 61 - 66.

[3] Woo Sook-Bin, Hellstein JW, Kalmar JR. Systematic Review: Bisphosphonates and Osteonecrosis of the Jaws. Ann Intern Med. 2006; 144: 753 - 761.

[4] Marx RE. Pamidronate (Aredia) and Zoledronate (Zometa) induced avascular necrosis of the jaws: A growing epidemic. J Oral Maxillofac Surg. 2003; 61: 1115.

[5] Migliorati CA. Bisphosphonates and oral cavity avascular bone necrosis: J Clin Oncol. 2003; 21: 4253.

[6] Carter GD, Gross AN. Bisphosphonates and avascular necrosis of the jaw. Aust Dent J. 2003; 48: 268.

[7] Wang J, Pogrel MA. Osreonecrosis of the jaws associated with cancer chemotherapy. J Oral Maxillofac Surg. 2003; 61: $1104-1107$. 
[8] Ruggiero SL, Mehrotra B, Rossenberg TJ, et al. Osreonecrosis of the jaws associated with the use of Bisphosphonates: a review of 63 cases. J Oral Maxillofac Surg. 2004; 62: $527-534$.

[9] Bagan JV, Murillo J, Jimenez Y, et al. Avascular jaw osteonecrosis in association with cancer chemotherapy: series of 10 cases. J Oral Pathol Med 2005; 34: 120 - 3.

[10] Hoefert S. Kieferknochennekrosen als mogliche unerwunschte Wirkung von Bisphosphonaten. Mund Kiefler Gesichtschirurg 2005; 9: 233 - 238.

[11] Lugassey G, Rea S. Severe osteomyelitis of the jaw in long term survivors of multiple myelome: anew clinical entity. Am J Med 2004; 117: 440 - 1.

[12] Melo M. Osteonecrosis of the maxilla in a patient with a history of bisphosphonate therapy. J Canadian Dental Association 2005; 71: 11 - 3.

[13] Migliorati C, Douglas E, Seneda L. Bisphosphonate-associated osteonecrosis of mandibular and maxillary bone. An emerging oral complication of supportive cancer therapy. Am Cancer Soc 2005; 104: 83 - 93.

[14] Schirmer I, Reochart PA, Durcop H. Bisphosphonate und Osteonecrosen im Kieferberiech. Mund Kiefler Gesichtschirurg 2005; 9: 239 - 45.

[15] Schwartz HC. Osteonecrosis and bisphosphonates: correlation versus causation (comment). J Oral Maxillofac Surg. 2004; 62: 763 - 4.

[16] Marx RE, Sawatari Y, Fortin, et al. Bisphosphonate-Induced Exposed Bone (Osteonecrosis/ Osteopetrosis) of the Jaws: Risk Factors, Recognition, Prevention and Treatment. J Oral Maxillofac Surg. 2005; 63: 1567 - 1575.

[17] Mavrokokki T, Cheng A, Stein B. Nature and Frequency of Bisphosphonate-Associated Osteonecrosis of the Jaws in Australia. J Oral Maxillofac Surg. 2007; 65: 415 - 423.

[18] Chapurlat RD, Delmas PD, Liens D, et al. Long-term effects of intravenous pamidronate in fibrous dysplasia of bone. J Bone Miner Res 1997; 10: 1746 - 1752

[19] Chapurlat RD, Hugueny P, Delmas PD, et al. Treatment of fibrous dysplasiaof bone with intravenous pamidronate: long-term effectiveness and evaluation of predictors of response to treatment. Bone 2004; 35: 235 - 242.

[20] Liens D, Delmas PD, Meunier PJ, et al. Long-term effects of intravenous pamidronate in fibrous dysplasia of bone. Lancet 1994; 343: 953 - 954.

[21] Lara R, Matarazzo P, Bertelloni Sq et al. Pamidronate treatment of bone fibrous dysplasia in nine children with McCune-Albright syndrome. Acta Paediatr 2000; 89: 188 $-193$.

[22] Fleisch H. Bisphosphonates: mechanisms of action. Endocr. Rev. 1998; 19: 80 - 100

[23] Fournier P, Boissier S, Filleur S, et al. Bisphosphonate inhibit angiogenesis in vitro and testosterone-stimulated vascular regrowth in the ventral prostate in castrated rabs. Cancer Res. 2002; 15: 6538 - 6544. 
[24] Lin JH, Russel G, Gertz B. Pharmacokinetics of alendronate: an overview. Int J Clin Pract Suppl. 1999; 101: $18-26$.

[25] Rogers MJ, Russel RG. Overview of bisphosphonates. Cancer 1997; 80: 1652 - 60

[26] Hughes DE, Uy HL, Sasaki A, et al. Bisphosphonates promote apoptosis in murin osteoclasts in vitro and in vivo. J Bone Miner Res. 1995; 10.

[27] Bartl R. Bisphosphonate. Manual Supportive Massnahmen und symptomorien tierte Therapie. Munchen, 2001; $184-90$.

[28] Carano A, Konsek JD, Schlesinger PH, et al. Bisphosphonates directly inhibit the bone resorption activity of isolated avian osteoclasts in vitro. J Clin Invest 1990; 85: $456-61$

[29] American Assosiation of Oral and Maxillofacial Surgeons. American Assosiation of Oral and Maxillofacial Surgeons Position Paper on Bisphosphonate-Related Osteonecrosis of The Jaws; J Oral Maxillofac Surg. 2007; 65: 369 - 76.

[30] Green JR. Bisphosphonates: preclinical review. Oncologist. 2004; 9 Suppl 4: 3 - 13.

[31] Hughes DE, Mcdonald BR, Russel RG, et al. Inhibition of osteoclast-like cell formation by bisphosphonates in long-term cultures of human bone marrow. J Clin Invest. 1989; 83: $1930-5$.

[32] Vitee' C, Fleisch H, Guenther HL. Bisphosphonates induce osteoblasts-mediated resorption. Endocrinology. 1996; 137: 2324 - 33.

[33] Bilezikian JP. Osteonecrosis of the jaw - Do Bisphosphonates Pose a Risk? N Engl J Med 2006; 2278 - 81.

[34] Tarasoff P, Csermak K. Avascular necrosis of the jaws: risk factor in metastatic cancer patients J Oral Maxillofac Surg. 2003; 61: 1238-1239.

[35] Berenson J, Hirschberg R. Safety and convenience of a 15-minute infusion of zolendronic acid. Oncologist 2004; 9: 319 - 329.

[36] Marketos M. The top 200 brand drugs in 2003 (by units). Drug Topics 2004; 148: 76 86.

[37] Mehrotra B, Ruggiero S. Bisphosphonate complications including Osteonecrosis of the Jaw. American Society of Hematology, $356-360$.

[38] Agrillo A, Petrucci MT, Mustazza MC, et al. New Therapeutic Protocol in the Treatment of Avascular Necrosis of the Jaws. Mutaz B. Habal 2006; 1080 - 1083.

[39] Bamias A, Kastritis E, Bamia C, et al. Osteonecrosis of the jaw in cancer after treatment with bisphosphonates: Incidence and risk factors. J Clin Oncol 2005; 23: 8580 8587.

[40] Rossi D, D'orto O, Pagani D, et al. Bisphosphonate-associated osteonecrosis of the jaws: a therapeutic dilemma. OOOOE; 103: $1-5$. 
[41] Polizzotto MN, Cousins V, Schwarer AP. Bisphosphonate-associated osteonecrosis of the auditory canal [Letter]. Br J Haematol 2006; 132: 114.

[42] Estilo CS, Van Poznak CH, Williams T, et al. Osteonecrosis of the maxilla and mandible in patients treated with bisphosphonates: a retrospective study. Proc Am Soc Clin Oncol. 2004; 22: 750.

[43] Chiandussi S, Biasotto M, Dore F, et al. Clinical and diagnostic imaging of bisphosphonate-associated osteonecrosis of the jaws. Dento-maxillofacial Radiol 2006; 35: $236-43$.

[44] Dunstan CR, Felsenberg D, Seibel M. Therapy Insight: the risk and benefits of bisphosphonates for the treatment of tumor-induced bone disease. Nature Clinical Practice Oncology, January 2007, vol. 4, №1, 42 - 55.

[45] Dannemann C, Gratz KW, Riener MO, et al. Jaw osteonecrosis related to bisphosphonate therapy. A severe secondary disorder. Bone 2007; 40: 828 - 834 .

[46] Pozzi S, Marcheselli R, Sacchi S, et al. Bisphosphonate-associated osteonecrosis of the jaws: a review of 35 cases and an evaluation of its frequency in multiple mieloma patients. Leukemia and Lymphoma, 2007; 48 (1): 56 - 64.

[47] Favia G, Pilolli GP, Maiorano E. Histologic and histomorphometric features of bisphosphonate-related osteonecrosis of the jaws: An analysis of 31 cases with confocal laser scanning microscopy. Bone 2009; 45 (3): 406 -413.

[48] Goss AN. Bisphosphonate-associated osteonecrosis of the jaws. Climacteric 2007; 10: $5-8$.

[49] Corso A, Varettoni M, Zappasodi P, et al. A different schedule of zoledronic acid can reduce the risk of the osteonecrosis of the jaw in patients with multiple myeloma. Leukemia 2007; 1 - 4 .

[50] Durie BG, Katz M, Crowley J. Osteonecrosis of the jaw and bisphosphonates. N Engl J Med 2005; 353: 99 - 102.

[51] Badros A, Weikkel D, Salama A, et al. Osteonecrosis of the jaw in Multiple Myeloma Patients: Clinical Features and Risk Factors. J Clin Oncol 2006; 24: 945 - 952.

[52] Clarke B, Boyette J, Vural E, et al. Bisphosphonates and jaw osteonecrosis. The UAMS experience. Otolaryngology - Head and Neck Surgery 2007; 136: 396 - 400.

[53] American Dental Association Council on Scientific Affairs: Expert panel recommendations: Dental menagement of patients receiving oral bisphosphonate therapy. J Am Dental Assoc 2006; 137: 1144 - 1150.

[54] Tosi P. Osteonecrosis of the jaw in patients with multiple mieloma, treated with bisphosphonates: Evidence of increasing risk after treatment with zolendronic acid. Haematologica 2006; 91: 968 - 971 
[55] Nastro E, Musolin C, Allegra A, et al. Bisphosphonate-Associated Osteonecrosis of the Jaw in Patients with Multiple Myeloma and Breast Cancer. Acta Haematol 2007; 117: $181-187$

[56] Update Recommendation of the Prevention, Diagnosis, and Treatment of Osteonecrosis of the Jaw in cancer patients. Basel, Novartis, May 2006

[57] Graziani F, Cei S, La Ferla F, et al. Association Between Osteonecrosis of the Jaws and Chronic High-Dosage Intravenous Bisphosphonate therapy. The Journal of Craniofacial Surgery 2006; 17: 876 - 879.

[58] Clavo B, Catala L, Perez JL, et al. Ozozne therapy on cerebral blood flow\& a preliminary report. Evidence-based Comlementary and Alternative Medicine 2004; 1: 315 319.

[59] Hellstein JW, Marek CL. Bisphosphonate induced osteochemonecrosis of the jaws: an ounce of prevention may be worth a pound of cure. Spec Care Dentist 2006; 26: 8- 12

[60] Landis BN, Richter M, Dojcinovic I. Osteonecrosis of the jaw after treatment with bisphosphonate. BMJ 2006; 333: 982 - 983.

[61] Migliorati C, Casiglia J, Epstein J, et al. Managing the care of patients with bisphosphonate-associated osteonecrosis: an American Academy of Oral Medicine position paper. J Am Dent Assoc 2005; 136: 1658 - 1668.

[62] Package Insert Revisions re: Osteonecrosis of the jaw: Zometa (zoledronic acid) injection and Aredia (pamidronate disodium) injection. Oncologic Drugs Advisory Committee Meeting, March 4, 2005.

[63] Shane E, Goldring S, Christakos S, et al. Osteonecrosis of the jaw: more research needed. J Bone Miner Res 2006; 21: 1503 - 1505 
